\title{
"A LUTA NÃO TEM FIM": UNA EXPERIENCIA DEL MOVIMIENTO SOCIAL Y DE EDUCACIÓN POPULAR EN EL BRASIL ENTRE 1985 Y 1987
}

\section{"A LUTA NÃO TEM FIM"2: AN EXPERIENCE OF SOCIAL MOVEMENTS AND POPULAR EDUCATION IN BRAZIL BETWEEN 1985 AND 1987}

\author{
Vera lucia Ermida Barbosa \\ Universidad de Coimbra. Portugal \\ Hélia Roly Cunha \\ Alcaldía Municipal de Angra dos Reis RJ. Brasil
}

\section{RESUMEN}

A partir de la década de 1980 América Latina presentó una fuerte tendencia de crecimiento de los movimientos de masas. En el caso brasileño los referentes teóricos y morales de la teología de liberación y de la educación popular tenían un papel determinante en la redemocratización tras la dictadura militar que se instaló en el país en 1964. En este escenario político e ideológico se desarrolló la lucha por vivienda que dio origen al documental titulado "A Luta não Tem Fim". Analizar esta experiencia nos puede dar pistas para avanzar en las reflexiones sobre los movimientos sociales en el actual escenario poscolonial y decolonial.

Palabras clave: Movimientos sociales; educación popular; transformación social; poscolonialismo; decolonialidad

\footnotetext{
ABSTRACT

From the 1980s onwards, there was a sharp rise in the growth of mass movements. In the case of Brazil, the theoretical and moral references of liberation theology and popular education played a key role in the re-democratisation process following the military dictatorship which began in 1964. The struggle for housing arose within this political and ideological framework and gave rise to the documentary entitled "A Luta não Tem Fim" ("The Fight has no End"). Analysing this experience can provide us with clues to promote reflections on social movements in the current post-colonial and decolonial scene.
}

Keywords: Social movements, popular education, social transformation, postcolonial, decoloniality.

1 Traduce: La Lucha no Tiene Fin.

2 Translation: The Fight Has no End 


\section{INTRODUCCIÓN}

Los movimientos sociales son acciones sociopolíticas construidas por actores sociales colectivos pertenecientes a diferentes estratos sociales, articuladas en ciertos escenarios de coyuntura socioeconómica y política de un país, constituyen un campo político de fuerza social en la sociedad civil. Estas acciones se concretizan por medio de estrategias locales diferenciadas, que toman la forma de denuncias, acciones directas y presiones indirectas. (GOHN, 2000: 11). En el caso de "A Luta não Tem Fim" es posible identificar estas tres formas de acciones estratégicas, pero antes cabe contextualizar y problematizar el escenario en que esta 'lucha' se dio.

Los movimientos sociales latinoamericanos vivieron a partir de la década 1980 una fuerte tendencia de crecimiento, principalmente aquellos definidos como movimientos de masas. En el caso brasileño los referentes teóricos y morales de la teología de la liberación y del movimiento pedagógico creado por Paulo Freire, llamado educación popular, inspiraron a militantes, religiosos, intelectuales y movimientos sociales cumpliendo un papel determinante en la reorganización del movimiento obrero y campesino. Dichos referentes fueron gestados durante los años 70 del siglo XX, cuando los movimientos sociales inventaron espacios de debate para contraponerse al autoritarismo del régimen militar y buscar mejores condiciones de vida. Estas luchas se apoyaban en la concepción de sujetos colectivos que impulsaban la creación de nuevas formas jurídicas y patrones de legitimidad que valorizaban las demandas sociales definidas colectivamente en la práctica política por ciudadanos históricos comprometidos con la transformación social (GOHN, 2000), Esta actuación priorizaba los procesos educativos al lado de grupos populares con una perspectiva emancipadora de consciencia ciudadana. La estrategia, inspirada en los trabajos teóricos marxistas de Antonio Gramsci, impulsó la fundación de tres grandes fuerzas sociales que surgieron en el Brasil en la década de 1980: la Central Única dos Trabalhadores (CUT), el Partido dos Trabalhadores (PT) y el Movimento dos Trabalhadores Sem Terra (MST). Estos eventos hicieron parte del proceso de redemocratización del Brasil y de un proyecto de transformación más radical de la sociedad brasileña. 
En el periodo de la dictadura militar en el Brasil (la cual se instaló con el golpe militar de 1964), se controló y restringió la libertad de expresión. De la misma manera se controló la asociación de individuos, grupos políticos y sociales, que criticaron el régimen político autoritario. Sin embargo, pudieron darse algunos espacios de movilización y debate en la base de la sociedad brasileña y al final de la década de 1970, debido a la intensa presión social, el régimen militar "promovió" una gradual abertura política.

Este escenario político e ideológico compone el contexto en el que se dio la lucha por la vivienda de 18 familias sin abrigo en el municipio de Niterói (Estado de Rio de Janeiro). Este proceso llamó la atención de la opinión pública, consiguiendo el apoyo de la Universidade Federal Fluminense y de la Organização dos Advogados do Brasil (OAB). De esta manera, se lideró un movimiento que presionó poderes públicos y movilizó a intelectuales, juristas, militantes, políticos y medios de comunicación de la época, siendo hasta el día de hoy un ejemplo de organización basada en la educación y participación popular y un retrato de cómo los movimientos sociales actuaban en el Brasil durante la década de 1980.

El video titulado "A Luta não Tem Fim"3 ${ }^{3}$ es resultado del material registrado durante los dos años en que acompañamos a este movimiento popular. La creación, libreto, producción, selección de escenas y banda sonora fueron producto de la metodología participativa de la educación popular. Consideramos que reflexionar sobre esta experiencia y sobre el momento histórico vivido en el Brasil durante la década de 1980, puede darnos pistas para avanzar en la reflexión sobre este tema en el escenario actual; posmoderno y decolonial, cabe recordar que este periodo es reconocido en el país como una incubadora de movimientos sociales y de redemocratización.

\section{1. "Los Movimientos" en el Brasil}

\subsection{Golpe, Régimen Dictatorial y Movimientos Sociales}

El Brasil hizo parte de un largo periodo de dictaduras en América Latina, siendo el más largo de ellos y el que más avanzó en la adaptación de las instituciones políticas al nuevo orden autoritario y militarista. Por más de una década, la realidad latinoamericana se convirtió en el escenario de golpes, que instalaron regímenes militares en diversos países de la región (Brasil, 1964; Argentina, 1966; Perú y Panamá, 1968; Ecuador, 1972; 
Chile, 1973; Argentina, nuevamente, junto con Uruguay en 1976; entre otros). La complejidad y las consecuencias de este capítulo histórico no serán tratadas aquí, sin embargo, algunas consideraciones se hacen necesarias en el sentido de avanzar en la comprensión del escenario brasileño en de la década de 1980, cuando se realizó el documental "A Luta não Tem Fim".

Sobre los años que precedieron al golpe, Fico (2004) considera que,

Las transformaciones estructurales del capitalismo brasileño, la fragilidad institucional del país, las inseguridades que marcaron el gobierno de João Goulart, la propaganda política del IPES ${ }^{4}$, la idiosincrasia golpista de los conspiradores (especialmente de los militares); todas son causas macroestructurales o micrológicas que deben ser tenidas en cuenta, no habiendo ninguna fragilidad teórica al considerar como razones para el golpe tanto las condiciones estructurales, como los procesos coyunturales o los episodios inmediatos. (FICO, 2004: 56)

Durante muchos años las investigaciones sobre los factores que permitieron el golpe ${ }^{5}$, se depararon con el silencio de los propios militares. En las fases más cerradas del régimen, este tema podía generar problemas políticos y de seguridad para los investigadores. Este contexto favoreció a los militares con algunas variables tangentes a los hechos.

Este escenario comenzó a cambiar, según Soares (1994), al final de la década de 1970 y principalmente en los años subsecuentes cuando el sigilo ya no era obligatorio y salieron a la luz algunas publicaciones de militares de alto rango producidas durante la dictadura ${ }^{6}$. Así fue posible saber quiénes conformaron el grupo de conspiradores y obtener nuevos elementos para llenar algunos vacíos producidos por el silencio que la dictadura impuso ${ }^{7}$.

4 Instituto de Pesquisas e Estudos Sociais fundado en 1961 por empresarios brasileños y representó una fuerte oposición al gobierno de João Goulart.

5 Que dio inicio a los 21 años de régimen militar en el Brasil.

6 Mourão Filho (1978), Portela (1979) y Guedes (1979).

7 Las investigaciones que fueron fundamentales para el estudio del golpe de 1964 y de la dictadura militar se desarrollaron por investigadores del CPDOC - Centro de Pesquisa e 
En el Brasil, tal como en los países latinoamericanos que vivieron historias de represión militar en este periodo, había motivaciones especificas relacionadas con intereses locales de orden económico, político, ideológico, social y cultural. Consideramos complejo determinar el inicio de un momento histórico, sin embargo, aceptaremos la afirmación de Soares (1994), según la cual el golpe de 1964 tuvo su origen en 1961, con la renuncia del presidente Jânio Quadros y la eminente sucesión de João Goulart, "Jango".

La renuncia de Jânio colocó al Brasil, en particular a los militares, frente a la posibilidad de ser presidido por un político de izquierda, con claras vinculaciones con el aparato sindical y relaciones ordinarias con los comunistas. La fe anticomunista, que permeaba y permea la corporación militar, se sintió acorralada. (SOARES, 1994: 33).

Los estudios del CPDOC (Centro de Pesquisa e Documentação de História Contemporânea do Brasil), basados en entrevistas a militares, muestran cuales eran las motivaciones y preocupaciones de estos agentes para llevar acabo el golpe y las cuales se categorizaron por este centro de investigación en tres bloques: (a) la preocupación por el caos administrativo y el desorden políico; (b) la preocupación por el peligro comunista e izquierdista en general y (c) la preocupación por los ataques a la jerarquía y a la disciplina militar (SOARES, 1994: 31 ). Otros aspectos señalados por el CPDOC, apuntan a las acciones desestabilizadoras (como la propaganda ideológica y la movilización de la clase media, entre otras), fomentadas de forma articulada por el IPES (Instituto de Pesquisas e Estudos Sociais) y otras agencias de la conspiración golpista cívico-militar.

Sin la desestabilización política el golpe hubiera sido difícil, pero sin la iniciativa militar hubiera sido imposible, sin embargo, la acción militar no fue planeada con toda la seguridad y la sistematicidad del caso.

El golpe de 1964 significó, según Codato (2005), la modificación decisiva de la función política de los militares en el Brasil. De manera distinta a las usuales operaciones militares intermitentes realizadas con el claro objetivo de combatir el "desorden", el "comunismo" y la "corrupción", los

Documentação de História Contemporânea do Brasil, de la Fundação Getúlio Vargas. Sobre obras recientes que usaron archivos producidos por el régimen militar brasileño ver: FICO, C. (2008). Disponible en http://linux.an.gov.br/seer/index.php/info/article/viewFile/86/68. Acceso el 26 de enero/2016. 
militares hicieron de esta modificación una intervención permanente que buscaba instalar un mandado de carácter represivo, autoritario y dictatorial, controlando primero el gobierno (al Ejecutivo), luego el Estado (y sus múltiples aparatos) y finalmente la escena política (instituciones representativas).

La "amenaza comunista" que hacia parte de la lista de motivaciones numeradas por los militares para dar el golpe de 1964, estaba vinculada principalmente a los movimientos sociales, los cuales se fortalecieron, se hicieron más combativos y movimientos como las Ligas Camponesas do Nordeste y el Movimento dos Agricultores Sem-Terra en el sur del país, colocaron en la agenda política la urgente cuestión de la reforma agraria. En el área de educación y cultura popular surgieron movimientos en todo el país como el Movimento de Educação de Base (MEB) iniciado por las Iglesia Católica, el Movimento de Cultura Popular (MCP), la Campanha de Educação Popular (CEPLAR), los Círculos Populares de Cultura (CPC), la experiencia de alfabetización de adultos con el Método Paulo Freire en Angico, (Estado de Rio Grande del Norte), la Campaña "De Pé no Chão também se Aprende a Ler" y la União Nacional dos Estudantes (UNE). Al mismo tiempo, en el campo laboral el sindicalismo industrial presentó graves conflictos: entre sindicatos oficiales y sindicatos de oposición, entre empresarios y el Ministerio del Trabajo. (FAVEIRO, 1983; GOHN, 2000)

En marzo de 1964 se interrumpió este ciclo de movilizaciones y de organización popular con la creación de leyes y nuevos aparatos burocráticos de control, como el Acto Institucional n5 de diciembre de 1968 (AI5), en el que se cazaba y castigaba cualquier manifestación individual o colectiva, estableciendo severas y violentas restricciones a los derechos sociopolíticos de los ciudadanos. Se inauguró así una era de miedo, represión y violación de los derechos humanos, siendo parte de la tendencia de los gobiernos militares que se expandieron por toda América Latina (GOHN, 2000).

La crisis económica y social abrió una grieta que favoreció la emergencia de los nuevos movimientos sociales ${ }^{8}$ (NMS) que se insertaban en el debate y en el campo de acción, con significados culturales e identidades psicológicas (ALEXANDER, 1998; MELUCCI, 1980) y haciendo énfasis en

8 Los movimientos sociales considerados clásicos, profundamente influenciados por la vertiente marxista, se apoyan en categorías como hegemonía, contradicciones urbanas y luchas sociales. Su énfasis se apoyaba en la toma y en la reformulación completa del poder económico y político. En este camino el proceso revolucionario se presentaba como condición indispensable para establecer un orden emancipador. 
la autonomía e identidad de los movimientos sociales defensores de la libertad o de la emancipación, en las luchas populares urbanas por bienes, equipos colectivos y derecho a la posesión de la tierra (LACLAU, 1983, 1987; KRISCHKE, 2000; SOUSA SANTOS, 2001; GOHN, 2011). Estos actores dieron otra perspectiva al proceso político en el cual la participación de las bases populares se daba fuera de los lugares institucionalizados y jerárquicos. En este nuevo espacio de discusión por derechos en el escenario político, las acciones colectivas introdujeron un nuevo sujeto que se relacionó con el Estado a partir de diferentes mecanismos de interlocución. La relación con la política en la sociedad brasileña ha estado históricamente marcada por la cultura de la dependencia, la no participación y una ciudadanía regulada por el clientelismo, el asistencialismo y el paternalismo estatal e institucional. La politización del cotidiano hizo posible la creación de organizaciones por medio de la democracia participativa y creó espacios de debate y de enfrentamiento al régimen dictatorial. Según Sousa Santos (2001) los nuevos movimientos sociales innovan en el campo ideológico y en las formas organizativas y son originales por la "impureza" ideológica, la diversidad de objetivos, de ideologías y de bases sociales; valorizando la participación efectiva de todos los actores sociales en el espacio de la sociedad civil con la perspectiva de crear una nueva cultura política. "La novedad de los NMS no reside en el rechazo de la política, sino (al contrario), en la ampliación de la política hasta más allá del marco liberal de la distinción entre estado y sociedad civil." (SOUSA SANTOS, 2001: 181).

Conectados por la demanda popular y por la participación de la Iglesia, los nuevos movimientos sociales en el Brasil encontraron en la teología de la liberación ${ }^{9}$ un importante agente dinamizador. Con la fundación de las CEB (Comunidades Eclesiais de Base) y de las pastorales como CPT (Comissão Pastoral da Terra), la CPO (Comissão Pastoral Operária) y el $\mathrm{CIMI}$ (Conselho Indígena Missionário) se organizaron miles de personas y se originaron movimientos populares combativos, que formaron comités de apoyo a las innumerables huelgas que se dieron en el Brasil entre 1978-

9 La teología de la liberación fue desarrollada en América Latina por F. Gutiérrez y en el Brasil se destacaron los hermanos Leonardo y Clódovis Boff. Según orientaciones del Concilio Vaticano 11 de 1964, y del Congreso de Medellín - Colombia en 1968, la teología de la liberación reorganizó las prácticas religiosas católicas. Se aproximaron de las demandas populares y redefinieron algunas concepciones adoptando lecturas marxistas sobre las estructuras de dominación. La concepción de actor social activo en lucha por la justicia social se volvió el tonó de las discusiones a la luz de la Biblia. 
1979. En el campo de la educación surgieron movimientos asociativos de trabajadores de la educación básica ${ }^{10}$, la educación secundaria ${ }^{11}$ y el $3^{\circ}$ Grado ${ }^{12}$. Las centrales sindicales fueron reactivadas, surgiendo la Confederação Geral dos Trabalhadores (CGT) y la Central Única dos Trabalhadores (CUT).

La década de 1980 marcó al continente por configurase como un rico semillero de movimientos sociales, principalmente los movimientos de masas que cuestionaron las dos matrices sucesivas, básicas y totalizantes que constituyeron en el siglo XX el campo político latinoamericano: el liberalismo y el populismo. (SOUSA SANTOS, 2001; LACLAU, 1983). El proceso de reapertura política del Brasil trajo consigo importantes movimientos populares que buscaban la reparación de las violencias cometidas a lo largo del régimen militar.

El fin del periodo militar y la reapertura democrática (que culminó en las elecciones directas para presidente de la República en 1989), se relaciona al contexto histórico y sociopolítico de 1984, cuando la campaña Diretas $J^{\prime} a^{13}$ movilizó a millones de personas en todo el país.

El Brasil aprobó la nueva Constitución Federal en 1988, en la cual los movimientos sociales (que surgieron al final de la década de 1990 y se consolidaron en los años siguientes), inscribieron leyes como derechos, que fueron contempladas en la Carta Magna igual que varias reivindicaciones históricas. Estas conquistas sociales de trabajadores, mujeres, niños y ciudadanos; hasta entonces considerados minorías subalternas, fueron en gran parte construidas al interior de los movimientos populares en los cuales la educación popular se hizo presente.

10 Ensino Fundamental.

11 Ensino Meio.

$123^{\circ} \mathrm{Grau}$.

13 La sucesión presidencial hizo parte del proceso de abertura política y de redemocratización. En 1984 el Partido del Movimiento Democrático Brasileño (PMDB), en un intento por cambiar las reglas de las elecciones presidenciales propuso una reforma constitucional que restableciera el voto directo y lanzó la campaña de las "Diretas Já" con el objetivo de obtener apoyo popular para la aprobación de la reforma, llevando a los partidos de oposición a unirse para movilizar a la población. El resultado de la campaña "Diretas Já" fue una impresionante movilización popular con millones de personas participando en mítines en todo el país. Al observar esa movilización daba la impresión de que la sociedad civil (que había mostrado su existencia en los movimientos sociales surgidos en 1978) había despertado decididamente y, finalmente, alteraría el curso de la liberalización. Sin embrago, la reforma fue derrotada en el Congreso, una vez que la presión popular no fue lo suficientemente eficaz para hacer frente a todas las maniobras usadas por el gobierno para evitar su aprobación. 


\subsection{Reapertura Política, Educación Popular y Movimiento Social}

A lo largo de la segunda mitad del siglo XX muchas experiencias relacionadas con la concepción de la educación popular se desarrollaron en América Latina (BRANDÃO, 1984, 2006; GADOTTI \& TORRES, 1994; PAIVA, 2003). Esa diversidad de movimientos sobre esa denominación no permitió conceptualizar de forma exacta lo que es la educación popular. No obstante, el examen histórico de ese campo nos direcciona para por lo menos tres movimientos que se entrecruzaron desde el inicio del siglo XX. En primer lugar, los trabajos de educación escolar y prácticas de formación de cuadros entre los trabajadores. En segundo lugar, el movimiento de educadores e intelectuales por la escuela pública y por la democratización. En tercer lugar, los movimientos y campañas de alfabetización de adultos (FLEURI, 2002: 55).

La educación popular dentro del paradigma latinoamericano surge historicamente como contrapunto a los procesos de dominación económica, política y cultural, derivados de los países centrales del capitalismo del siglo XX. En ese contexto, la cuestión del conocimiento se constituyó como uno de los puntos centrales de los movimientos que promovieron la educación popular como proyecto de emancipación de los oprimidos (FLEURI, 2002: 55). Construida a partir de los saberes movilizados en la lucha por reconocimiento y por dignidad, la educación popular asumió directrices políticas de diversas orientaciones que convergieron en el enfrentamiento de las situaciones deshumanizantes fomentadas por la explotación capitalista.

Un breve análisis histórico de los procesos sociales y políticos del Brasil desde la década de 1960, se muestra como la educación popular y los movimientos sociales estuvieron intensamente relacionados. Los movimientos sociales populares se constituyeron como espacios de continuo enfrentamiento y en procesos permanentes de construcción de saberes, en donde las necesidades populares se transformaron en demandas sociales. En este proceso, la educación popular se configuró no sólo como una actividad pedagógica, siendo también como una configuración de trabajo colectivo en sí misma, es decir, el momento en que la vivencia del saber compartido, crea la experiencia del poder compartido (BRANDÃO, 2006):

La educación popular como práctica de la libertad (FREIRE, 1999) se concretaba en acciones educativas que buscaban crear espacios autónomos, donde el manejo del poder y del saber se daba dentro de una relación entre iguales. En esta perspectiva las formas educativas de carácter participativo y la reflexión colectiva de la práctica de los propios actores eran privilegiadas. En la concepción de Paulo Freire la problematización 
y la construcción de la consciencia crítica se daba por medio de la lectura del mundo.

La constitución del método de la educación popular comenzó a estructurarse como cuerpo teórico y práctica social en el Brasil a finales de la década de 1950, cuando intelectuales y educadores relacionados a la Iglesia Católica e influenciados por el humanismo personalista (que florecía en Europa en la postguerra), se concentraron sobre los asuntos populares. Paulo Freire (1921-1997) fue el pionero en el trabajo de sistematizar teóricamente la educación popular, en el libro Pedagogía del Oprimido de 1966. (FREIRE, 2003).

La educación popular puede ser entendida como un esfuerzo de movilización, organización y capacitación científica y técnica de las clases populares. En este sentido es fundamental relacionar la dimensión educativa con la dimensión histórica, con el compromiso explícito de tratar las cosas del pasado, encontrando vidas y pensamientos de las personas comunes, para ser registrados. Así, en el presente, "[...] nuestro problema es también desnudar las suposiciones, igualmente pretenciosas, de aquellos que piensan saber lo que son los hechos y las soluciones que quieren imponer a las personas" (HOBSBAWM, 1998: 230).

El conocimiento crítico deconstruye la historicidad del ser y del saber, revelando los límites y posibilidades de cada situación. Desnaturalizando ideologías dominantes que invaden las experiencias e iluminando las dinámicas formativas constituyentes del yo, se configura en una "pedagogía verdaderamente crítica, acogiendo con totalidad la importancia de la intuición, de los sentimientos y de las emociones, por su valor epistemológico y también por su capacidad para alcanzar un modo saludable de ser en el mundo." (GLASS, 2013: 840).

En la perspectiva freireana, el objetivo es aliar la educación a un proyecto histórico de emancipación social: las prácticas educacionales deberían estar relacionadas a una teoría del conocimiento. Consecuentemente la educación aparece como acto de conocer, no como una simple transmisión del conocimiento o del equipaje cultural de una sociedad. Una vez que conocimiento y poder son considerados totalmente relacionados, tradiciones y prácticas culturales en la enseñanza, por ejemplo, están sobre sospecha de disimular relaciones de dominación.(TORRES, 1997: 70).

La teoría y la práctica de Paulo Freire marcaron profundamente los movimientos sociales, cruzaron fronteras disciplinares y geográficas. Al tiempo 
que sus reflexiones fueron profundizado el tema que el persiguió durante toda su vida - la educación como práctica de la libertad - sus abordajes influenciaron otros campos del conocimiento, creando raíces en los más variados suelos, fortaleciendo teorías y prácticas educacionales en un ejercicio de pensamiento transdisciplinar.

Una pedagogía planetaria definida por Dussel (1996, 2002, 2006), que se apoya en el surgimiento de una consciencia ético-crítica y una acción educadora que busca no solo una mejoría cognitiva, sino también la producción de una consciencia ético-crítica que se origina en el proprio sujeto, que por ser sujeto histórico es privilegiado con su propia liberación. De este modo, el acto pedagógico crítico se ejerce en el proprio sujeto y en su práctica transformadora.

A mediados de la década de 1980, con el fin de la dictadura militar en el Brasil, muchos de los estudiantes, profesores, técnicos, intelectuales y líderes populares que participaron de las experiencias semiclandestinas de educación popular durante la represión política pasaron a asumir cargos y funciones de jefatura en las instituciones públicas, principalmente en las universidades. La educación popular bien como los movimientos sociales ganaron espacios oficialmente en la vida universitaria y las investigaciones participativas se convirtieron sinónimo de investigación innovadora y progresista. El interés estudiantil acompañó este movimiento que creció en los cursos relacionados a las áreas sociales y humanas, principalmente, fortaleciendo la conquista de espacio de los proyectos de extensión. (VASCONCELOS, 2011). La experiencia en educación popular titulada "A Luta não Tem Fim" se desarrolló en este escenario histórico político e ideológico, que marcó definitivamente a todos los que en ella participaron.

\section{UNA EXPERIENCIA ACTUAL}

\section{1. "A Luta não Tem Fim": Una experiencia en Educación Popular}

La experiencia aquí presentada se dio entre 1985 y 1987, periodo en que un grupo de alumnas ${ }^{14}$ del curso de Servicio Social de la Universidade Federal Fluminense acompañó y registró la lucha por vivienda de 18 fa-

14 El grupo era compuesto de cuatro alumnas: Hélia Roly Cunha, Luz Maria Durans Matos, Marilene Schlottgen Kraus y Vera Lúcia Ermida Barbosa sobre la orientación de la profesora Laís Helena Pinto Veloso. 
milias de la (para la época denominada) Favela do Morro do Estado, hoy llamada Comunidade do Morro do Estado ${ }^{15}$.

La historia de la ocupación del Morro do Estado está registrada desde el inicio del siglo pasado, según el Decreto Municipal n 255 de 02 de abril de 1914, en el que se autorizaba la construcción de habitaciones provisorias en diversos cerros ${ }^{16}$ de la ciudad de Niterói en el Estado de Rio de Janeiro, incluyendo al Morro do Estado (AZEVEDO, 1987). En 1980 el municipio de Niterói tenía 436.155 habitantes y contaba con 29 favelas que albergaban a 35.000 personas. En 1990 el Morro do Estado, una de las mayores favelas del municipio, tenía una población estimada de 3.533 habitantes, distribuidos en 0,19 km2 (IBGE, 1991). Se convirtió en barrio en 1986 por la ley 4.895 de 08/1 1/86, con una ocupación caracterizada por la fuerte segregación espacial en relación a los barrios vecinos, sin reglamentación de tierras y sin servicios de infraestructura. Los habitantes con baja escolaridad tenían una interacción heterogénea en el mercado de trabajo, desarrollando actividades sin reglamentación laboral y con un rendimiento mensual medio de $1 / 2$ a 1 salario mínimo (CODESAN, 1981: 102).

El Morro do Estado se configuraba como campo de práctica profesional de las alumnas y alumnos del curso de Servicio Social de la Universidade Federal Fluminense (UFF) en la década de 1980. Una aproximación, como se dijo anteriormente, que hizo parte del escenario político e ideológico del proceso de abertura política por el cual pasaba el país, el cual favoreció los estudios, investigaciones y extensiones universitarias junto a las comunidades y movimientos sociales.

Con base a este movimiento nacional y los hechos concretos que causaron la perdida de sus casas a decenas de familias del municipio, se dio inicio al movimiento de lucha por la vivienda de las 18 familias que protagonizan este relato.

En enero de 1985 funcionarios de la Alcaldía Municipal de Niterói, agentes de la Defensa Civil y un contingente policial realizaron el despojo arbitrario de habitantes que poseían sus casas construidas junto a las pendientes, en lo alto de la Favela Morro do Estado. El riesgo de deslizamientos de tierra a causa de las fuertes lluvias era inminente, haciendo necesaria la retirada de las familias, pero esta acción fue acompañada

15 Sobre el debate acerca de estos términos ver: CASTRO (2004). Disponible en: http://www. revista.ufpe.br/revistaanthropologicas/index.php/revista/article/view/45/42. Acceso el 07 de feb. 2016.

16 En portugués: morro. 
por la demolición total de las viviendas sin que a los habitantes les fuera permitido retirar sus pertenencias.

Mi casa era ahí, yo viví ahí, yo viví 47 años, ahí yo fui a la escuela. La policía nos mandó salir de ahí. Entraron en mi casa. Me dijeron que si no salía me hacía responsable de lo que les pasara a los niños. Dijeron que el cerro se iba a caer, pero yo me quedé dentro resistiendo y el (policía) me dijo que me iba a llevar presa. Entonces dejé todo [...]y él me dijo: - Entonces mañana, cuando sean las ocho el empleado de la Alcaldía viene aquí para sacar las cosas de la casa. Usted viene y le abre (la casa) para que él entre y saque las cosas. Cuando llegué ahí, ellos ya habían abierto y derrumbado todo. Mi colchón desapareció, mi fregadero desapareció, mi vaso sanitario desapareció... cama, armario de ropa, nevera, televisor y sofá. Me quedé sin nada. (M.C. Habitante. Vídeo "A Luta não Tem Fim". 1987).

La ausencia de políticas públicas dedicadas al problema habitacional y consecuentemente al problema de políticas de prevención para la ocupación de las pendientes, con mapeo de las áreas de riesgo, obras de contención, regularización de la tierra y de acciones en el campo educativo, se expresa en la inadecuada y (a veces) violenta conducta de la política.

De las familias que quedaron sin techo, 18 fueron alojadas en la escuela municipal del proprio Morro do Estado, donde permanecieron por cinco meses en condiciones precarias, aguardando una solución por parte del poder público. Después de este período fueron trasladadas para unidades habitacionales de emergencia construidas en forma de "vila ${ }^{17 "}$ por la Alcaldía Municipal de Niterói en el mismo cerro. La unidad habitacional designada a cada familia estaba compuesta por un cuarto y un baño, tenía una dimensión de $3 \times 4 \mathrm{~m} 2$, con instalación de energía eléctrica, pero sin instalación hidráulica dentro del domicilio, lo que obligaba a los habitantes a traer agua en latas desde lugares distantes.

Organizadas con el apoyo de sectores de la sociedad civil, la Universidade Federal Fluminense (UFF) - Escola de Serviço Social (ESS) y la Ordem dos Advogados do Brasil (OAB) - Seção de Direitos Humanos, las familias 
desalojadas iniciaron un proceso que movilizó a los medios de comunicación, líderes comunitarios ${ }^{18}$ y representantes del poder público municipal y estadual.

El movimiento se inició a partir de la carta que los habitantes enviaron a la OAB - Seção de Direitos Humanos con el apoyo de la UFF-ESS en mayo de 1985 solicitando la designación de un abogado para mediar las negociaciones junto al poder público.

Consideramos que debemos tener nuestro derecho a la vivienda garantizado. Resaltamos aquí, que teníamos nuestras casas que con nuestro sacrificio construimos [...], fuimos prácticamente expulsados de nuestras casas. Así que creemos que lo más justo es que los responsables del derrumbamiento de nuestras casas deban responsabilizarse por el daño que tuvimos y proponer inmediatamente una solución que garantice condiciones necesarias y dignas para nuestra sobrevivencia. (BARBOSA, 1987: 130).

Entre octubre de 1986 y julio de 1987 fueron realizadas ocho audiencias en la sede de la Alcaldía Municipal de Niterói, con la presencia de las 18 familias, la Asociación de habitantes del Morro do Estado (AMME), el Abogado de la $O A B$ - Derechos Humanos, el equipo de alumnas de la UFF - ESS, el equipo del Núcleo de Audio Visual (NAV) de la UFF, los técnicos de la Alcaldía Municipal de Niterói y del Gobierno Estadual de Rio de Janeiro, la Compañía de Agua y Alcantarillado (CEDAE), la Compañía de Electricidad de Rio de Janeiro (CER) y la Defensa Civil.

El contenido de las reuniones realizadas en la Alcaldía era debatido críticamente en las reuniones comunitarias semanales, con una perspectiva política e ideológica a partir de la cual se construían nuevas estrategias. Estas reflexiones contaron con el apoyo del equipo de alumnas del curso de Servicio Social de la UFF y sirvieron para politizar, organizar y motivar, no sólo el movimiento, sino también a los actores individuales.

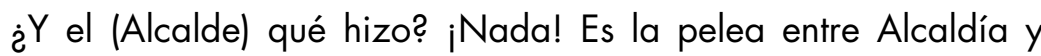
Estado, ni el Estado hace, ni la Alcaldía hace nada, nadie pidió

18 La acción de los líderes comunitarios de Niterói se encontraba organizada y avanzaba en las reivindicaciones junto al poder público. Ver Carta de Reivindicaciones, disponible en http:// urbanismo.niteroi.ri.gov.br/arquivos_biblioteca/planejamento/planodiretor 1992/CartaDeReivindicacaoDasAssociacoesDeMoradores.pdf. Acceso en 07 de feb. 2016. 
esto. El Alcalde nos colocó en esta situación y estamos esperando una respuesta de él. Nuestra situación está de la forma que está, un juego de "empurra, peteca"19, uno lo lanza para allá, otro lo lanza para acá. Nadie quiere hacer nada por nadie, nadie quiere hacer nada por nosotros ¿̇Por quée ¿̇Por qué somos pobres? ¡No! Ellos tienen más poder que nosotros, somos nosotros quienes los ayudamos a ellos, porque somos nosotros que ayudamos a ellos, a través de votos. $\mathrm{Si}$, un presidente sabe, si un Gobernador sabe, que quien les da los votos es el pueblo, ¿̇Sí o no? Entonces ¿¿Qué es lo que ellos tienen que hacer por el pueblo? ¿Qué es lo que ellos hacen por nosotros? ¡Nada! (E. Habitante. Video "A Luta Não Tem Fim". 1987).

En esta perspectiva, el movimiento no solo busca la solución al problema específico que el gobierno generó, sino también y fundamentalmente, el avance en el proceso de participación social y política que se da en la organización y movilización popular. Por medio de las reuniones semanales en las que se instrumentalizaban las acciones políticas y se articulaba una nueva cultura política.

Yo les estoy dando un plazo a ellos aquí, yo no quiero más agua, yo continúo recogiendo el agua del grifo, yo continúo recogiendo agua en la misma lata. Yo quiero que se cumpla el plazo que le estoy dando al doctor aquí... yo solo vuelvo aquí con este plazo cumplido. Si no se cumple, nadie necesita volver a ninguna reunión. Nosotros vamos hacer nuestras casas en el mismo lugar. Todo el mundo vuelve. ¿Qué es lo que podemos hacer? ¿Vamos a vivir en aquel lugar apretado? Les estoy hablando a ellos, yo no quiero nada de agua, nada de luz, yo no quiero nada de eso ¡Yo quiero mi casa! yo no quiero saber cuánto tengo que pagar. Después de todo, si es asunto de pagar, si cobran un millón por mes, los demando. Porque realmente ellos no están dándome nada, ellos me están devolviendo una cosa que era mía y encima de todo voy a tener que pagar el valor de la mano de obra. (E. Habitantes. Vídeo "A Luta não Tem Fim". 1987).

19 Esta expresión hace referencia hace referencia a un juego popular brasileño, donde se pasa la "peteca". En este contexto de enunciación los habitantes quieren decir que el gobierno del Estado y la Alcaldía se están pasando de un lado al otro el problema sin darle una solución. (Nota de la traductora) 
Durante una de las reuniones comunitarias sobre el tema de la organización del movimiento y de las estrategias de movilización, los habitantes, ya cansados de la larga espera y de la negligencia de las autoridades, optaron por denunciar a través de los medios de comunicación, para llamar la atención de las autoridades y de la sociedad en general. Las precarias condiciones de vida, las promesas no cumplidas y el juego político serían los hechos a denunciar. A partir de esta demanda del movimiento surgió de una las habitantes la siguiente idea, "¿Ya pensó? ¡Nuestra historia da hasta para hacer una película!". (BARBOSA, 1987: 26).

Fue el primer paso para pensar en la posibilidad de documentar la historia y la lucha utilizando el video como un instrumento de denuncia y presión desde otra perspectiva, que también fuera un video construido colectivamente configurándose como una contra ideología a los medios de comunicación masivos y de rescate de la cultura popular, un vehículo de educación popular desvelando las contradicciones y apoyando la organización, teniendo como enfoque la participación protagonista de los habitantes, los cuales interpretaron el video contribuyendo con la recuperación y construcción de sus identidades culturales y la comprensión de los determinantes que desencadenaron la cuestión social.

Los pasos para viabilizar la idea fueron dados con el apoyo de la Escola de Serviço Social y Núcleo de Audio Visual de la UFF.

Siguiendo la perspectiva de la educación popular las etapas de construcción del libreto, definición de lugares y personas para los registros, conducción de las filmaciones, edición, música y utilización del material finalizado, fueron objeto de discusiones colectivas. Las reflexiones colectivas que las filmaciones provocan después las sesiones de video feedback favorecieron el debate y permitieron ampliar los asuntos.

Este video no es solo nuestra vida, no, es la vida de mucha gente. Él va a ser una visión para mucha gente también, no es solo para nosotros. Con este video, realmente vamos a conseguir penetrar en algún lugar de la televisión, mostrando el final de la vida de nosotros aquí y cómo fue nuestra lucha. Ese video va a ser para mucha gente que está ahí hace quince años sin recibir su casa, y no ganó nada hasta hoy. Este video va a ser una preparación para que muchas personas sigan la misma causa que nosotros seguimos. Este video es una pauta de comunicación muy buena. (BARBOSA, 1987:78).

El registro en video de la narrativa de los habitantes sobre su historia y la trayectoria de su lucha por la vivienda, da la posibilidad de rescatar sus 
historias de vida por medio de la memoria individual y colectiva, generó importantes reflexiones sobre la inserción de ellos en la sociedad de clases.

En abril de 1987 el Alcalde Municipal de Niterói desapropió, con carácter urgente, por medio del Decreto $n^{\circ} 5020 / 87$, un área de $330 \mathrm{~m} 2$ en el Morro do Estado destinada a la construcción de las casas.

La experiencia en educación popular, con una perspectiva dialéctica, en la que estuvieron involucradas las 18 familias, las alumnas del curso de Servicio Social (más directamente), la NAV, la OAB, la AMME, el Poder Público Municipal y el Poder Público Estadual; representó una forma de actuación y de expresión popular a través del movimiento social. Su enfrentamiento con el Estado y la introducción de intelectuales ${ }^{20}$ comprometidos con las clases populares, se encaja en el escenario histórico de una década donde estos procesos florecían dejando valiosas enseñanzas, lo que los hace tan actuales.

\section{2. Las Décadas Siguientes y la Actualidad de la Experiencia}

La década de 1980 estuvo marcada por alteraciones en el escenario político y por la conquista fundamental de la aprobación de la Constitución de 1988, que reconoció como derechos las reivindicaciones históricas de los movimientos sociales, afirmando la legitimidad de la participación colectiva y redefiniendo profundamente la orientación y la acción de los movimientos con relación a la democracia.

En el escenario latinoamericano el final de la década de 1980 presentó un nuevo panorama en lo referente a la organización de los movimientos sociales, los movimientos de identidad.

Si los años 80 del siglo XX fueron un gran semillero de movimientos sociales y las luchas populares se tomaron las calles y llegaron al Congreso Nacional brasileño; la década de 1990 estuvo marcada por la crisis internacional del capitalismo globalizado (la llegada de esta al Brasil) y el retorno de las elecciones directas en todos los niveles gubernamentales, alteró la dinámica de las luchas sociales que pasaron a exigir la democratización del espacio público estatal y la implantación o profundización, a todo nivel, de las políticas neoliberales adoptadas por el gobierno federal en los primeros cinco años de esta década (como reflejo de la globalización mundial), generó nuevos desafíos: desempleo, reformas, precarización de

20 Sobre el concepto de intelectual orgánico al que se refiere el termino, ver: GRAMSCI, A. 1982. 
las condiciones laborales y grandes obstáculos a la reglamentación e implementación plena de la recién aprobada Constitución.

El análisis de los movimientos sociales en la contemporaneidad se introduce en un campo más amplio: el de la crisis de la modernidad y la emergencia de nuevas formas de racionalidad. En este debate, el tema referente a las relaciones de poder y dominación entre el Norte y el Sur (en el mundo), y consecuentemente la cuestión de la producción y reproducción de las relaciones sociales entre individuos, grupos y movimientos de la sociedad; apuntan para cuestiones históricas y actuales, políticas e ideológicas que son indispensables para esta reflexión.

El fenómeno designado "globalizaciones" está relacionado con la forma de las interacciones transnacionales y transfronterizas (SOUSA SANTOS, 2005). Se trata de un concepto en permanente construcción que asume otras designaciones de acuerdo con diversos teóricos ${ }^{21}$. Para Sousa Santos estos procesos de globalización son un "fenómeno de mutilación con dimensiones económicas, sociales, políticas, culturales, religiosas y jurídicas; interrelacionadas de modo complejo". (SOUSA SANTOS, 2005: 32).

La "globalización" dibujada por los Estados centrales del sistema mundial, desde mediados de la década de los años ochenta, con el llamado "consenso neoliberal" o "consenso de Washington", se difundió mundialmente con el consenso hegemónico que definió el futuro de la economía mundial, las políticas de desarrollo y especialmente el papel del Estado en la economía. Aunque las prescripciones apunten en dirección a la economía, sus dimensiones y las consecuencias van más allá de este campo, la globalización social o "globalización de la pobreza" (CHOSSUDOVSKY, 1997 apud. SOUSA SANTOS, 2005: 41) es una de las consecuencias, que se trata de la reducción de los costos salariales, de los derechos laborales y de la adopción de medidas compensatorias de combate a la pobreza, en lugar de medidas de combate a la desigualdad.

La vulnerabilidad económica hizo de los países periféricos y semiperiféricos los principales objetos para las imposiciones de esta receta neoliberal. Las consecuencias son percibidas a través de los datos conexos a las desigualdades, ya que las tres décadas siguientes son drásticas en lo que

21 Sobre el tema ver: "Globalización" (FEATHERSTONE, 1990; GIDDENS, 1990; ALBROW y KING, 1990), "Formación Global" (CHASE-DUNN, 1991), "Cultura Global" (APPADURAI, 1990, 1997; ROBERTSON, 1992), "sistema global" (Sklair, 1991), "Modernidades Globales" (FEATHERSTONE et al., 1995), "Proceso Global" (FIERDMAN, 1994), "Cultura de la Globalización" (JAMESON Y MIYOSHI, 1998) ○ "Ciudades Globales" SASSEN, 1991, 1994; FORTUNA, 1997). 
concierne a la desigualdad y a la distribución de la riqueza mundial.

En este escenario de desigualdades que se instaló con gran intensidad en la década de 1990, se tornó una tendencia el discurso hegemónico de la globalización, basado en una falsa invisibilidad de las jerarquías del sistema mundial que continua vigente hasta la actualidad, siendo que realmente hay una intensificación de las jerarquías y de las desigualdades. Según Wallerstein (1992) el capitalismo es un proceso histórico que no resulta de una historia lineal que se desarrolla de manera natural, por el contrario es el resultado de las múltiples interacciones de un conjunto de fenómenos que lo tornan posible, el 'descubrimiento' de América se convierte en el inicio del proceso de expansión global del capitalismo, de la ciencia y del sistema interestatal (entre otros aspectos), que marcan la historia hasta los días de hoy, la cual es grabada por la colonialidad 22 .

En esta perspectiva, Quijano (2014) considera que la colonialidad se localiza al interior de la globalización en curso, siendo parte del proceso que dio origen a esta misma.

Tuvo inicio con la "constitución de América Latina y del capitalismo colonial/moderno eurocéntrico como nueva norma de poder mundial sobre la idea de raza, una construcción mental que expresa la experiencia básica de la dominación colonial y que desde entonces impregna las dimensiones más importantes del poder mundial, incluyendo su racionalidad específica, el eurocentrismo. (QUIJANO, 2014: 109).

La década de 1990 estuvo marcada también por la emergencia de los movimientos de reflexión, gestados desde los años 50 del siglo $\mathrm{XX}^{23}$, tomaron fuerza y cuestionaron los fundamentos de la narrativa unívoca $y$ etnocéntrica de la Modernidad. La crisis de la racionalidad occidental perturba con más intensidad tales fundamentos, ya que cada vez son menos

22 El concepto de colonialidad fue elaborado por primera vez por Aníbal Quijano (1991). La colonialidad es un fenómeno histórico complejo que se extiende hasta nuestro presente y se refiere a una norma de poder que opera a través de la naturalización de la jerarquías territoriales, raciales, culturales y epistémicas, posibilitando la reproducción de relaciones de dominación. Esta norma de poder no solo garantiza la explotación por el capital de unos seres humanos por otros a escala mundial, sino también la subalternización y la obliteración de los conocimientos, experiencias y formas de vida de los que son así, dominados y explotados.

23 Sobre este tema ver QUIJANO, A (1956). 
capacez de cumplir las promesas que la legitimaron, como paz, liberdad, igualdad, progreso, prosperidad y solidariedad. Siendo así, las reflexiones que toman fuerza en América Latina son un marco. (SOUSA SANTOS, 2005).

La reflexión decolonial ${ }^{24}$ trajo la cuestión del eurocentrismo como centro del proyecto modernidad/colonialidad, proponiendo la decolonización de la historia narrada y del pensamiento historiográfico imperial. Según Arturo Escobar (2005), podemos decir que para este grupo la fuerza orientadora es una reflexión continuada sobre la realidad cultural y política latinoamericana, incluyendo el conocimiento subalternizado de los grupos explorados y oprimidos.

En esta medida, la decolonización del poder, del saber y del ser, se colocan como cuestión fundamental en el pensamiento decolonial y en la busqueda de construir nuevas formas de expresión del poder, del conocimiento y de la subjetividad a partir del Sur. (MIGNOLO, 2010).

Estos contextos están presentes y se suman con otros aspectos del escenario posmoderno, como la constitución de sociedades (en constante, rápida y permanente cambio) marcadas por la experiencia de transformaciones permanentes y por una forma reflexiva de vida, donde "las prácticas sociales son constantemente examinadas y reformadas a la luz de las informaciones recibidas sobre aquellas propias prácticas, alternando, así, constitutivamente, su carácter." (GUIDDENS, 1990: 37-8 apud. HALL, 2005: 15).

Bajo este escenario Global, actual e histórico y sus impactos a nivel local, los movimientos sociales se movieron en diversas direcciones. En la década de 1990 el formato de actuación adoptado durante los años 70 y 80 del siglo XX (con las manifestaciones en las calles, la educación popular y el trabajo de base junto a grupos populares) fue dejado de lado y considerado una estrategia anticuada de lucha. Los movimientos sociales urbanos se rearticularon interna y externamente, en su papel dentro de la sociedad. "El asociativismo predominante en los años 90 no se deriva de procesos de movilizaciones masivas, y sí de procesos de movilizaciones

24 Aunque el pensamiento decolonial haya sido implantado a partir del inicio de la colonialidad, su genealogía y su nombre fueron recientemente propuestos por intelectuales del grupo modernidad/ colonialidad. Sus principales miembros son: Aníbal Quijano, Walter Mignolo, Edgardo Lander, Ramón Grosfoguel, Santiago Castro-Gómez, Catherine Walsh, Nelson Maldonado-Torres, Zulma Palermo, Fernando Coronil, Eduardo Restrepo, Agustín Lao Montes, Freya Schiwy, Sajinés Javier, José David Saldívar y Arturo Escobar. 
puntuales" (GOHN, 2000: 26), ya que la participación directa en el poder público influenció esta dinámica. Otros actores sociales surgieron en la sociedad civil como las ONG, que después de apoyar los movimientos sociales en las décadas de 1970 y 19080, asumieron nuevos papeles en asociación con el Estado a través del tercer sector, entrando en la agenda de las nuevas políticas sociales y prestando servicios esenciales.

Con la crisis interna de los movimientos sociales se deslumbraba una crisis mayor, que se reflejaba en la vida cotidiana del país. Bajo la bandera neoliberal se adoptaron políticas que descentralizaron cada vez más al Estado y a las políticas públicas: el desmonte violento de políticas sociales y su substitución por las asociaciones con el tercer sector; la fragmentación de la sociedad debido a la desorganización del mercado de trabajo (subempleo e informalidad) y la descalificación de la mano de obra frente al avance de la tecnología y el crecimiento de la violencia con el resultado de la agudización de las desigualdades, generaron un campo fértil para el crecimiento de redes de poder paralelo relacionadas al narcotráfico y al comercio ilegal de armas, los cuales contribuyeron a la desmovilización de la población.

Después de casi una década de desmovilizaciones, los movimientos sociales volvieron al escenario político nacional en los años 2000. Para Gohn (2015) "los oprimidos desarrollaron culturas de resistencia (a veces calladas, a veces ruidosas), ya que la situación se perpetuaba con cambios históricos en el escenario político y económico." (GOHN, 2015: 41). Así, impulsadas fuertemente por el movimiento indígena y el Movimento Sem Terra (MST), las movilizaciones vuelven a hacer parte del escenario nacional, antiguas y nuevas categorías marcan sus posiciones, entre estas el movimiento de estudiantes, profesores, camioneros y subempleados.

A lo largo de la primera década del siglo XXI, las ONG, transformadas en gran parte en "tercer sector" y con una fuerte tendencia a la despolitización, adoptaron una cultura política que "de cierta forma, fue resonante con las políticas neoliberales conservadoras, pues algunas de sus entidades descalificaban todo lo que era progresista de los años 80 , como arcaico y no moderno" (GOHN, 2000: 30). En ese sentido, las acciones colectivas de participación de la población se transformó acciones en menos reivindicativas y más propositivas. Además, las $O N G$ y otras entidades originarias del ciclo militante participativo/reivindicativo/contestatario de la década de 1980, adoptaron un tipo de cultura política totalmente diferente, donde el deseo por la búsqueda de soluciones se apoyaba en una fuerza activa modulada por los derechos humanos y la voluntad política para alcanzar sus objetivos. 
Las ONG no substituyeron los movimientos sociales, pero se alimentaron de ellos, de sus experiencias y sus conquistas. En las dos últimas décadas el asociativismo brasileño volvió a tener visibilidad y centralidad. En este nuevo momento de su trayectoria también surgen actores que presionan por procesos de cambio social, y que proponen transformaciones en las políticas identitárias y en las maneras de pensar y actuar socialmente. Esto generó una modificación en los proyectos y culturas políticas, pues se presentan con una heterogeneidad de actores sociales y acciones de lucha. Los movimientos sociales siguen siendo un sujeto social colectivo, que no puede ser pensado disociado del contexto histórico y coyuntural, aunque se trate de movimientos de resistencia y protesta a la globalización y a la economía o movimientos que generan nuevas sociabilidades vía Internet. El reconocimiento de su identidad política debe estar apoyado en su proceso de lucha dentro de la sociedad civil y política, necesitando ser reconocida como una identidad ${ }^{25}$ política que se construye, por lo tanto, puede variar en contextos y coyunturas diferentes.

\section{Algunas Consideraciones}

La década de 1980 en el Brasil estuvo marcada por la autonomía de las conquistas políticas e ideológicas de la sociedad civil a través de los movimientos sociales, luego de 21 años de régimen militar dictatorial. La abertura política, la redemocratización, los sindicatos organizados y la creación del "Partido dos Trabalhadores" (PT), el "Movimento dos Sem Terra" (MST), los movimientos urbanos, la campaña "Diretas Já" y la aprobación de la Constitución de 1988 (la cual transformó en ley las reivindicaciones populares) fueron conquistas sociales centradas en la ciudadanía colectiva. En un momento en el cual se avanzó en el trabajo de la educación de las bases y en las metodologías participativas originadas en la década de 1960 "A Luta não Tem Fim" se configuró como una experiencia de educación popular con la perspectiva de tornar concretos los derechos individuales, que reflejaban los derechos colectivos en que se formaron.

La construcción colectiva del video constituyó en un doble instrumento de politización. Por un lado, en cuanto proceso de aprendizaje y de autonomía, por otro, como herramienta política de lucha y de presión. Se trató de una experiencia que buscó poner en práctica la afirmación según la cual "quien enseña aprende al enseñar, y quien aprende enseña al aprender" (FREIRE, 1996: 25). 
A lo largo de la década de 1990 la descentralización del sujeto y la emergencia de una pluralidad de actores, trajo en primer plano la escena de la ciudadanía. En las décadas siguientes tomaron mayor dimensión las identidades de grupos, antes dispersos y desorganizados, proyectando en sus participantes un sentimiento de pertenencia social. Como escenario de estas identidades plurales, los movimientos sociales siguieron realizando un diagnóstico sobre la realidad social y construyendo propuestas, continuaron actuando en redes, construyendo acciones colectivas de resistencia a la exclusión, buscando la inclusión social; así como los movimientos de los años 80 del siglo XX siguieron construyendo representaciones simbólicas afirmativas por medio de discursos y prácticas (GOHN, 2011).

La contextualización de todos estos elementos es indispensable para entender no sólo la realidad brasileña, sino también la latinoamericana y la Global. Sí la globalización agudiza las desigualdades sociales mundialmente, los países del Sur afectados históricamente por la exclusión social como regla dominante, son profundamente golpeados. Es en este escenario los movimientos sociales contra la globalización vienen creciendo como grupos libertarios y emancipados, dando un nuevo formato y trayendo nuevos actores (punks, darks, viejos hippies, indignados, Black Blocs sumados a los ya existentes: indios, negros, mujeres, LGBT, urbanos y rurales, entre otros), para enfrentar al fenómeno contemporáneo que está en la base de los problemas sociales; la naturalización de la injusticia, de la explotación y la pobreza en las mentes de la población que inhibe el desarrollo del pensamiento crítico. (SIRVENT, 2008).

En el campo teórico, las reflexiones poscoloniales y decoloniales, aunque no hayan sido construidas para explicar específicamente movilizaciones sociales, vienen revitalizando este debate, ya que se focalizan en puntos centrales acerca del proceso de dominación imperialista, colonialista y eurocéntrica, y con ellos en la apropiación del saber de los pueblos nativos, la expropiación de sus tierras y cultura. En esta perspectiva, tocan en lo que es esencial para la comprensión de los movimientos sociales en todos los tiempos, el contexto histórico.

¿Qué había de nuevo en la experiencia que llamamos aquí "A Luta não Tem Fim"? Y ¿Qué nos puede aportar en la actualidad?

Tal vez la gran novedad haya sido el no despreciar el contexto histórico, político y social de la década de 1980, con la visión de que la consciencia histórica es procesual y se elabora en un juego de tensiones, intercambios y posiciones entre los sujetos que componen una escena (GOHN, 2003). Está también la convicción de que la participación ciudadana debe nascer de estructuras participativas organizadas autónomamente en la sociedad 
civil y que el trabajo de base es fundamental para alimentar y fortalecer la representación colectiva en las esferas públicas. Esta historia nos muestra la importancia de haber valorado las experiencias acumuladas por el movimiento social y de transformar en prácticas uno de los principios fundamentales de la educación popular: "Nadie libera a nadie, nadie se libera solo: los hombres se liberan en comunión" (FREIRE, 2003).

Después de tres décadas nada parece más actual.

\section{Referencias}

ALEXANDER, J. C. (1998). Ação coletiva, cultura e sociedade civil: secularização, atualização, inversão, revisão e deslocamento do modelo clássico dos movimentos sociais. Revista Brasileira de Ciências Sociais, 5-31.

AZEVEDO, M. N. (jan de 1987). L'Impact des politiques urbaines sur le developpment Niterói: 1960-1980. PhD thesis. Paris, Universitè de Paris XII: Institut D'Urbanism de Paris.

BARBOSA, V. L. (agosto de 1987). "A Luta Não Tem Fim": uma experiência em Educação Popular. Tese de Licenciatura em Serviço Social. Niterói, Rio de Janeiro, Brasil: Universidade Federal Fluminense.

BRANDÃO, C. R. (1984). A questão política da educação popular. São Paulo: Brasiliense.

BRANDÃO, C. R. (2006). O que é Educação Popular? São Paulo: Brasiliense. CASTRO, J. P. (2004). Revista ANTHROPOLÓGICAS. Obtido em 07 de fev de 2016, de revista.ufpe.br: http://www.revista.ufpe.br/revistaanthropologicas/index.php/revista/article/view/45/42

CODATO, A. N. (nov de 2005). Scielo. Obtido em 25 de jan de 2016, de Site da sicelo.br: http://www.scielo.br/pdf/rsocp/n25/31113.pdf

CODESAN. (1981). Projeto: padrões habitacionais da população de baixa renda do município de Niterói. Rerlatório final. Morro do Estado. Niterói, Rio de Janeiro, Brasil: Prefeitura Municipal de Niterói.

DUSSEL, E. (1996). Filosofía de la Liberación. Bogatá: Nueva América.

DUSSEL, E. (2002). Ética da libertação na idade da globalização e da exclusão. Petrópolis: Vozes.

DUSSEL, E. (2006). Filosifía de la Cultura y la Liberación. México: UACM. ESCOBAR, A. (2005). Mundos y conocimientos de otro modo: el programa de investigación modernidad/colonialidad latinoamericano. Tabula Rasa, 58-86.

FAVEIRO, O. (1983). Cultura Popular e Educação Popular: memória dos anos 60. Rio de Janeiro: Graal. 
FERREIRA, M. \&. (Realizador). (1987). "A Luta não Tem Fim" [Filme].

FICO, C. (2004). Scielo. Obtido em 25 de jan de 2016, de Site da scielo: http://dx.doi.org/10.1590/S0102-01882004000100003

FICO, C. (jul/dez de 2008). linux. Obtido em 26 de jan de 2016, de Site da linux.an.gov.br: http://linux.an.gov.br/seer/index.php/info/article/ viewFile/86/68

FLEURI, R. (2002). A questão do conhecimento na educação popular: uma avaliação do seminário permanente de Educação Popular e de suas implicações epistemológicas. . ljuí: Unijuí.

FREIRE, P. (1996). Pedagogia da autonomia: saberes necessários à prática educativa. São Paulo: Paz e Terra.

FREIRE, P. (1999). Educação como prática da liberdade. Rio de Janeiro: Paz e Terra.

FREIRE, P. (2003). Pedagogia do oprimido. Rio de Janeiro: Paz e Terra.

GADOTTI, M. T. (1994). Educação popular: utopia latino americana. São Paulo: Edusp.

GLASS, D. R. (jul-set de 2013). scielo. Obtido em 28 de maio de 2015, de site da scielo.com: http://www.scielo.br/pdf/edreal/v38n3/08.pdf

GOHN, M. d. (jan/jun de 2000). 500 Anos de lutas sociais no Brasil: movimentos sociais, ONGs e terceito setor. Revista Mediações. v. 5, n. 1. Londrina, pp. 11-40.

GOHN, M. d. (2003). Movimentos sociais no início do século XXI: antigos e novos atores sociais. Petrópolis: Vozes.

GOHN, M. d. (2011). Os movimentos sociais na contemporaneidade. Revista Brasileira de Educação, 333-512.

GOHN, M. d. (29 de dez de 2015). polis. Obtido em 06 de fev de 2016, de site da polis.revues.org: http://polis.revues.org/11186

HALL, S. (2005). A identidade cultural na pós-modernidade. Rio de Janeiro, RJ: DP\&A Editora.

HOBSBAWM, E. (1995). A era dos extremos. São Paulo: Companhia das Letras.

HOBSBAWM, E. (1998). Sobre História. São Paulo: Cia. das Letras.

IBGE. (2014). ibge.gov.br. Obtido em 14 de abril de 2015, de ftp://ftp. ibge.gov.br/Indicadores_Sociais/Sintese_de_Indicadores_Sociais_2014/ SIS_2014.pdf

KRISCHKE, P. J. (2000). periódicos.ufsc. Obtido em 30 de jan de 2016, de Site Periódicos.ufsc.br.: https://periodicos.ufsc.br/index.php/cadernosdepesquisa/article/view/2182 
LACLAU, E. M. (1983). Anpocs. Obtido em 30 de jan de 2016, de Site da Anpocs.org.br: http://www.anpocs.org.br/portal/publicacoes/ rbcs_00_02/rbcs02_04

LACLAU, E. M. (1987). Hegemonía y estrategia socialista: hacia una radicalización de la democracia. Madrid: Siglo XXI.

MELUCCI, A. (1980). The new social moviments: a theoretical approach. Social Science Information, 199-226.

MIGNOLO, W. D. (2010). Desobediencia Epistémica: Retórica de la modernidad, lógica de la colonialidad Y gramática de la descolonialidad. Buenos Aires: Ediciones del Signo.

PAIVA, V. P. (2003). História da educação popular no Brasil: educação popular de adultos. São Paulo: Loyola.

QUIJANO, A. (1956). "José Carlos Mariátegui, ensayos escogidos". Lima: Primer Festival.

QUIJANO, A. (1991). Colonialidad y Modernidad Racionalidad. Perú Indígena. Lima. v. 13, n. 29, 11-20.

QUIJANO, A. (2014). Textos de Fundación. Buenos Aires: Ediciones del Signo.

SANTOS, B. d. (2001). Los nuevos movimientos sociales. Revista del Observatorio Social de América Latina/OSAL, 177-188.

SANTOS, B. d. (2005). Globalização: fatalidade ou utopia? Porto: Edições Afrontamento.

SIRVENT, M. (2008). Educación de adultos: investigación, participación, desafios y contradiciones. 2. ed. Buenos Aires: Minó Dávila.

SOARES, G. A. (1994). O golpe de 64. Em G. A. SOARES, 21 anos de regime militar:balanços e perspectivas (pp. 21-43). Rio de Janeiro: Fundaçõa Getúlio Vargas.

TORRES, C. A. (1997). Pedagogia da luta: da pedagogia do oprimido à escola pública popular. Campinas: Papirus.

VASCONCELOS, E. M. (2011). Educação Popular na formação universitária: reflexões com base em uma experiência. São Paulo: Hucitec.

WALLERSTEIN, I. (1992). "Creación del sistema mundial moderno". Em L. B. PEÑA, Un mundo jamás imaginado (pp. 201-209). Bogotá: Santillana. 